\title{
The impact of internet access on cloud computing research in Africa: Analysis of bibliometric and online search data
}

\section{Azubuike Ezenwoke \& Onyeka Emebo}

To cite this article: Azubuike Ezenwoke \& Onyeka Emebo (2020) The impact of internet access on cloud computing research in Africa: Analysis of bibliometric and online search data, COLLNET Journal of Scientometrics and Information Management, 14:2, 393-410, DOI: 10.1080/09737766.2021.1927881

To link to this article: https://doi.org/10.1080/09737766.2021.1927881

曲 Published online: 04 Jun 2021.

Submit your article to this journal ¿

Q View related articles ¿

View Crossmark data $־$ 


\title{
The impact of internet access on cloud computing research in Africa : Analysis of bibliometric and online search data
}

\author{
Azubuike Ezenwoke \\ Onyeka Emebo
}

\author{
Azubuike Ezenwoke* \\ Department of Computer and \\ Information Sciences \\ Covenant University \\ Ota, Ogun State \\ Nigeria
}

and

\section{Department of Computer Science \\ Landmark University \\ Omu-Aran \\ Kwara State \\ Nigeria

$$
\begin{aligned}
& \text { azu.ezenwoke@ } \\
& \text { covenantuniversity.edu.ng }
\end{aligned}
$$

\author{
Onyeka Emebo ${ }^{+}$ \\ Department of Computer and \\ Information Sciences \\ Covenant University \\ Ota, Ogun State \\ Nigeria \\ onyeka.emebo@ \\ covenantuniversity.edu.ng \\ * Corresponding Author
}

The objective of this paper is to uncover the relationship between internet penetration and cloud computing research output and to understand the connection between the interest in cloud computing on research outputs in cloud computing from African countries. For the period of 2009 to 2017 , bibliometric data on cloud computing research was retrieved from the Scopus database. Online search traffic data on the search term "cloud computing" was obtained from Google trends for the period under review. Our results show that there was a strong significant correlation between internet penetration and the total number of scholarly outputs within the given period for all countries studied, suggesting that an increase in internet penetration is directly proportional to increase in cloud computing research activities and outputs from a given region. The penetration of internet technologies contributes significantly to the advancement of research efforts and scholarly outputs in ICT-related endeavours.

Keywords: Cloud computing, Bibliometrics, Informetrics, Scientometrics, Google trends, Search traffic.

\section{Introduction}

Cloud computing is a popular paradigm for hosting and delivering services over the internet. Cloud computing is commonly also referred to as the fifth utility, alongside electricity, gas, water and telecommunication services (Al-Shammari \& Al-Yasiri, 2014). Cloud computing, being a model of internet-based service provisioning, enables dynamically scalable and virtualized resources (infrastructure, platform, and software applications) to be delivered 
and accessed as services. Three basic cloud computing delivery models exist, and they include Infrastructure-as-a-service (IaaS), Platform-as-a-Service (PaaS), and Software-as-aService (SaaS). With over \$677 billion spent on cloud services globally from 2013 to 2016, cloud computing has emerged as a phenomenon with a huge market potential in the IT landscape (Gartner, 2016).

Since the invention of the fundamental concepts for cloud computing in the sixties, and the popularization of the term in 2006, institutions in different countries have contributed to the research and development efforts of the domain. In recent times, there seems to be an increase in the quality of academic and research activities from some of Africa's higher institutions, as measured by both the webometric rankings and the institutional rankings published by the Times Higher Education. The rankings are indicative of the quality of research and academic activities in these African institutions. Nevertheless, there is a still significant difference in the volume of national contributions from developed countries to the production of cloud computing knowledge, compared to outputs from developing countries (Ezenwoke \& Igbekele, 2019).

A number of reports and studies have catalogued Africa's very low contribution to the global knowledge outputs (Blom et al., 2015; Duermeijer et al., 2018; Fonn et al., 2018). For instance, a report published on Elsevier's website revealed that while Africa accounts for about $12.5 \%$ of the world's total population, it contributes less than one per cent (1\%) to research productivity globally (Duermeijer et al., 2018). Like other areas of research, the low contribution to cloud computing research can be attributed to a number of factors including: the low rate of internet penetration, limited technical competency in cloud computing technologies, and abysmal government funding of research and development (Fonn et al., 2018; Tuitoek et al., 2012).

The internet has enabled collaboration, fast and easy dissemination of knowledge, and increased access to information at a scale unimaginable before its advent (Dumon, 2013). Furthermore, the internet has had a positive impact on research and teaching, as some researchers reported to have been more involved research activities and authoring scholarly articles owing to the availability of the internet (Sampath Kumar \& Manjunath, 2013). Since the advent of the internet in Africa in 1993, there has been a steady increase in Africa's connectivity to the internet. This development has impacted in no small way research and development efforts on the continent, particularly research efforts in the ICT domain, where cloud computing belongs.

Following the appreciable growth rate in internet penetration in African countries in recent times (International Telecommunication Union, 2018; Kemp, 2018), we hypothesized that this growth rate, together with the increase of interests in a subject domain, should culminate in higher research outputs from the region. Therefore, the goal of this paper is to measure the impact of internet penetration, the volume of online traffic data (which is an indication of interest) on the volume of research outputs in cloud computing research domain from African countries. More specifically, the objectives of this study are defined as follows: (a) to define the relationship between internet penetration and cloud computing research output from countries in Africa; and (b) to understand the connection between 
the interest in cloud computing, as measured by online search volume, on research outputs in cloud computing from Africa.

Over the years, the International Telecommunication Union have collected and reported the internet penetration data of all the countries of the world. These data are generated by using a carefully designed methodology and have formed the basis for national ICT policies in many countries. In addition, the analysis of online search traffic data is an approach to measure the popularity of a variety of topics; in other words, the topics or keywords searched on the internet from a given region reveal interests in a topic(s) from that region. This method has been applied to study interests and trends in computing (Carta et al., 2018; Rech, 2007; Weng et al., 2018); medicine and public health (Foroughi et al., 2016; Mavragani \& Ochoa, 2018; Nuti et al., 2014); economics and finance (Kholodilin et al., 2010; Preis et al., 2013; Woo \& Owen, 2019; Yelowitz \& Wilson, 2015); social sciences (CarrièreSwallow \& Labbé, 2013; Dergiades et al., 2018; Rivera, 2016). In this paper, the authors collected data on internet penetration, as well as data on the online search volume of the term "cloud computing" and the research outputs from the regions under consideration from the Scopus database. Thereafter, statistical analyses of the data collected were performed to achieve the goal of the paper.

The structure of the remaining part of this paper is as follows: section 2 describes the methodology adopted to carry out the study. The study results were presented in section 3, while the implications of the results are discussed in section 4 . The conclusion is presented in section 5 .

\section{Materials and Methods}

This section describes the methodology adopted to realize the objectives of this study.

\subsection{Data Collection}

\subsubsection{Bibliometric Data}

The bibliometric data on cloud computing research was retrieved from the Scopus database. The Scopus database is the largest abstract and citation database of peer-reviewed literature covering more than 39,000 titles from over 5,000 publishers (Elsevier, 2016). Specifically, keywords containing "cloud computing" were formulated to retrieve the bibliometric information of relevant documents to the keywords. The search query was framed as follows: (TITLE-ABS-KEY ("cloud computing*"). The search result returned 57,590 research documents that contained the "cloud computing" in their titles, abstracts, or keywords.

The national outputs were assessed to identify the top ten African countries with the highest publications before 2017. A threshold of 15 publications was used as the criteria for inclusion in this study. Countries with publications count below 15 were not considered. Nine African countries met the criteria, including, Morocco, Tunisia, Egypt, South Africa, Algeria, Nigeria, Sudan, Kenya and Ghana. A modified query (see Figure 1) based on the 


\section{TITLE-ABS-KEY ("cloud computing") AND PUBYEAR \\ BEF 2018 AND AFFILCOUNTRY ("Morocco" OR "Tunisia" OR "Egypt" OR "South Africa" OR "Algeria" \\ OR "Nigeria" OR "Sudan" OR "Kenya" OR "Ghana")}

\section{Figure 1}

\section{Search Query Used in Scopus Database}

identification of the countries that met the criteria was used to obtain the bibliometric data used in this study. The modified query returned an aggregate of 1,494 publications contributed by the nine countries earlier listed.

\subsubsection{Internet Penetration Data}

The internet penetration data from 2010 to 2017 of the nine African countries identified as the most productive in cloud computing research were obtained from data made available by the International Telecommunication Union (ITU) ${ }^{1}$. The ITU is an agency the United Nations for ICTs and is the most authoritative source for internet penetration data globally.

\subsubsection{Online Search Traffic Data}

According to Netmarketshare ${ }^{2}$, Google is the most used search engine in the world powering over $74 \%$ of internet searches globally, and have dominated the search engine space over the years. Online search traffic data was obtained from Google trends. Google Trends is Google's online platform used to analyze the popularity of top search queries on Google over a user-defined period. Users of Google Trends can also compare the relative search volume of searches between two or more term. We used the search term "cloud computing" with the date range set to January 1, 2009, to December 31,2017. Each of the top ten countries obtained from the bibliometric search was used as the filter to obtain the online search volume data used in this study. The other filters were set to "All categories" and limited to web search, as against news search, YouTube search, image search and Google shopping.

\subsection{Bibliometric and Statistical Analysis}

Studies in bibliometrics use statistical methods to scientific publications as part of quantitative research assessment framework to measure scholarly outputs, trends and impact (Vinkler, 2019). Bibliometric studies have been conducted to measure the regional and

1 https://www.itu.int/en/ITU-D/Statistics/Pages/stat/default.aspx

2 https://netmarketshare.com/search-engine-market-share.aspx 
national research trends and outputs, for example Zyoud et al. $(2017,2020)$ performed a bibliometric study on the groundwater and climate change research activities and from the Arab world. In another direction of work, Cai et al. (2015) bibliometric-based approach was employed to quantitatively review the trends in global cloud computing research during 2007-2013. The bibliometric analyses covered in this study include the yearly publication spread per country; publication counts per country; most productive institutions; most prolific author's per country; and citation analysis. We utilized the h-index to measure the research impact of authors, institutions, and countries. The h-index, or Hirsch index was originally proposed by Hirsh (2005) as an author-level metric for measuring scientific productivity. Since its advent its use has extended to measure research impact of research groups, institutions and also countries (Bornmann \& Daniel, 2009). An h-index of 50 means that a researcher has at least 50 publications with at least 50 citations each. be of interest. The h-index is an easily computable metric that estimates the significance and research impact of a researcher, institution, or country.

Since the internet penetration and scholarly outputs data are not normally distributed according to the Ryan Joiner normality test, this study employed the use of nonparametric statistics for analysis. Overall, the correlation between internet penetration and the cloud computing scholarly outputs was performed using Spearman rho's correlation coefficient. The spearman rho correlation coefficient was also used to identify how internet penetration in each country correlated with scholarly outputs from those countries. The confidence level was set to $95 \%$, as a non-corrected p-value of less than 0.05 was considered to be significant. All the statistical analyses were performed using version 15 of the SPSS package (IBM-Corp, 2019).

\section{Results}

\subsection{Internet Penetration}

An analysis of internet penetration (2010 to 2017) in the African countries that have contributed to cloud computing research in the region is shown in Figure 2. The trend in



Figure 2

Stacked Chart of internet Penetration (2010-2017) 
Figure 2 shows a steady increase in internet penetration from 2010 to 2017 for all the countries under study.

\subsection{Bibliometric Analysis}

A total of 1,494 documents were returned based on the search, with the yearly publication distribution shown in Figure 3. The number of publications has continued to increase with the annual growth rate of 1.07 over the period (2010 to 2017). The 1,494 documents have been cited 5,227 times between 2010 and 2018, and have an h-index of 28. The citation trend is shown in Figure 4, with the highest number of citations yet, in 2018 (i.e. 1,903 citations). The most cited publication is titled, "The management of security in cloud computing" (Ramgovind et al., 2010), and this publication has been cited 181 times. The publications consist of mostly conference proceedings (See Figure 5).



Figure 3

Yearly Publication Trends (2009-2017)

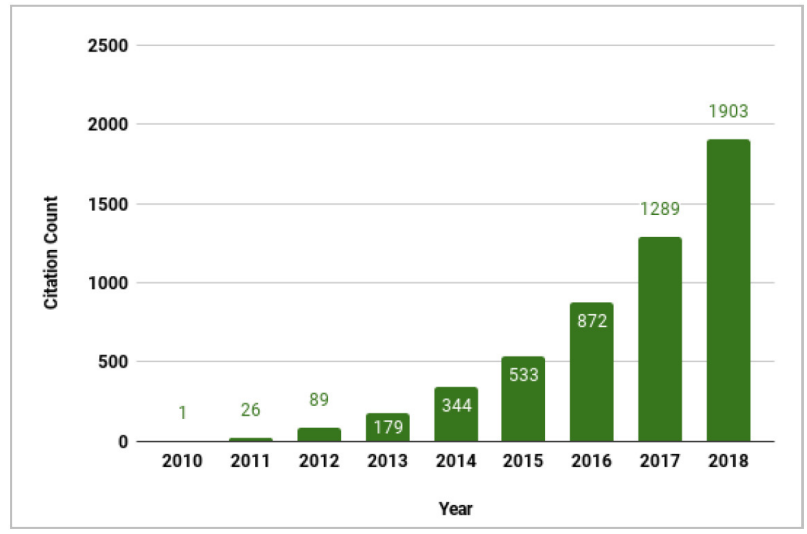

Figure 4

Citation Trends 




Figure 5

Distribution of the Publication Type (2010 to 2017)

\subsubsection{National Publication Distribution}

The number of publications attributed to countries that have contributed to cloud computing research in Africa is shown in Figure 6. Only five countries (including Egypt, Morocco, Tunisia and South Africa) have above 200 publications on the subject matter. Morocco tops the list with 358 publications, followed by Tunisia (313 publications). The contributions of other countries include Egypt (302 publications), South Africa (222 publications), Algeria (180 publications), Nigeria (75 publications). Sudan, Kenya and Ghana have less than 50 publications in the period under consideration).



Figure 6

Top Nine African Countries by Scholarly Outputs in Cloud Computing Research 


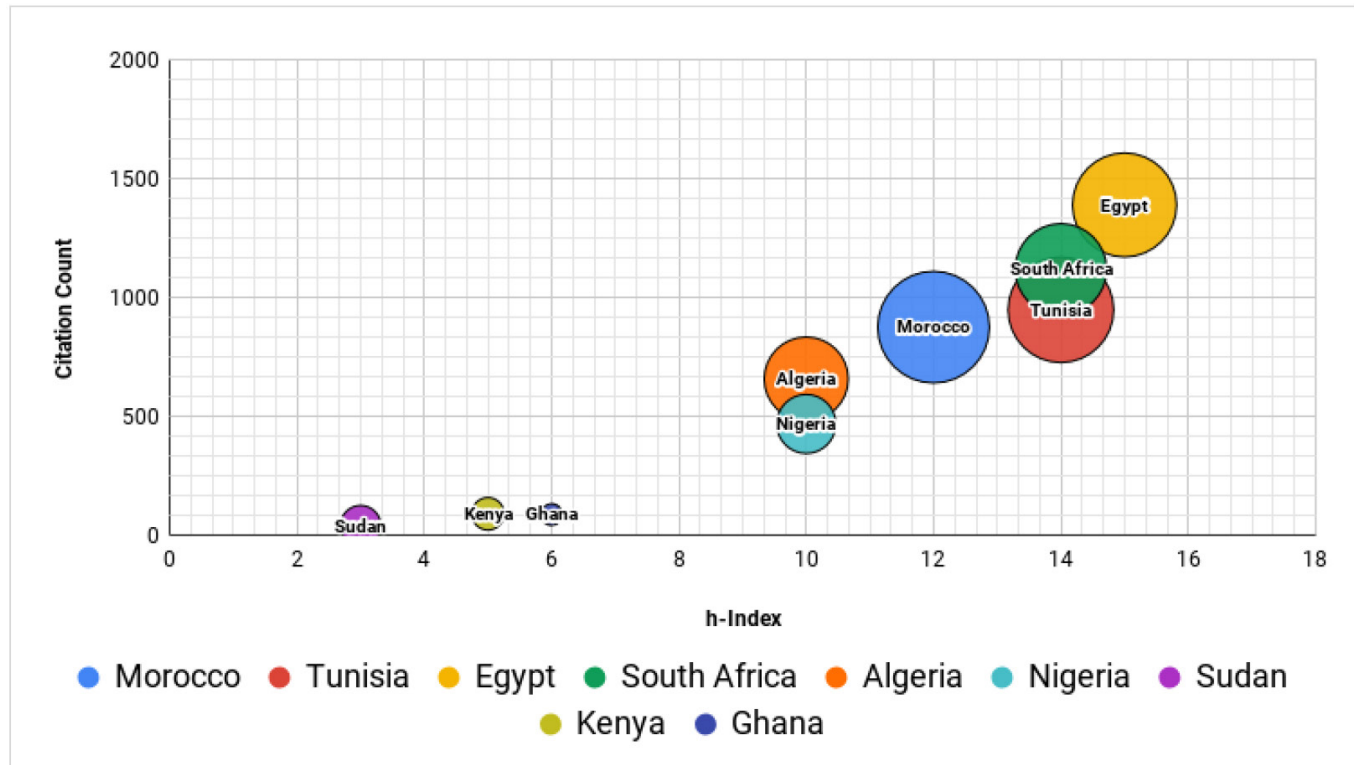

Figure 7

Bubble Chart showing Citation Counts (Y-axis), h-index (X-axis) and Number of Publications (Bubble Size) of the Top Nine Cloud Computing research-active Countries in Africa.

\subsubsection{National Citation Analysis}

An analysis of the national citation trend is presented in Figure 7. Egypt has the highest citation count and h-index among the African countries considered. Although Tunisia has more publications than South Africa, South Africa has a higher number of citation than Tunisia, while both countries rank equal in h-index. Sudan ranks the least in terms of citation count and h-index.

\subsubsection{Prolific Authors}

Table 1 contains the affiliation of the most prolific author, their number of publications and its percentage to the overall national output, as well as the citation count and the hindex of the authors in the given domain of cloud computing research. While comparing the most prolific authors from each country, Tolba, M. F of Ain Shams University, Cairo, Egypt, emerged with the highest number of publications (27), and second-highest citation count (76 citations), and shares the same h-index of 5 with the Venter, H.S., of the University of Pretoria, Pretoria, South Africa, who is credited with 17 and 59 publications and citations respectively. The most cited top author in this comparison is Belalem, G., of the Université d'Oran1, Oran, Algeria, as his research publications on cloud computing have been cited 82 times. 
Table 1

Most Prolific Cloud Computing Researchers in Each African Country

\begin{tabular}{|c|c|c|c|c|c|c|c|}
\hline$\#$ & Country & Name & Affiliation & $\begin{array}{c}\text { No. of } \\
\text { Publications }\end{array}$ & $\begin{array}{c}\text { \% of } \\
\text { National } \\
\text { Output }\end{array}$ & Citations & h-index ${ }^{+}$ \\
\hline 1 & Egypt & Tolba, M. F & $\begin{array}{l}\text { Ain Shams } \\
\text { University, Cairo }\end{array}$ & 27 & $8.9 \%$ & 76 & 5 \\
\hline 2 & Algeria & Belalem, G. & $\begin{array}{l}\text { Université d'Oran1, } \\
\text { Oran }\end{array}$ & 24 & $13.3 \%$ & 99 & 5 \\
\hline 3 & Morocco & Haqiq, A. & $\begin{array}{l}\text { Université Hassan } \\
\text { 1er, Settat }\end{array}$ & 20 & $5.6 \%$ & 49 & 4 \\
\hline 4 & $\begin{array}{l}\text { South } \\
\text { Africa }\end{array}$ & Venter, H.S. & $\begin{array}{l}\text { University of } \\
\text { Pretoria, Pretoria }\end{array}$ & 17 & $7.7 \%$ & 59 & 5 \\
\hline 5 & Tunisia & Boukadi, K. & $\begin{array}{l}\text { University of Sfax, } \\
\text { Sfax }\end{array}$ & 16 & $5.1 \%$ & 28 & 3 \\
\hline 6 & Nigeria & Misra, S. & $\begin{array}{l}\text { Covenant } \\
\text { University, Ogun }\end{array}$ & 12 & $16.0 \%$ & 42 & 3 \\
\hline 7 & Sudan & Yousif, A. & $\begin{array}{l}\text { Sudan University } \\
\text { Science and } \\
\text { Technology, } \\
\text { Khartoum }\end{array}$ & 5 & $16.1 \%$ & 4 & 1 \\
\hline 8 & Ghana & Adjei, J.K & $\begin{array}{l}\text { Ghana Institute } \\
\text { of Management } \\
\text { and Public } \\
\text { Administration, } \\
\text { Accra }\end{array}$ & 3 & $18.8 \%$ & 19 & 2 \\
\hline \multirow{3}{*}{9} & \multirow{3}{*}{ Kenya } & Gichoya, D. & $\begin{array}{l}\text { Moi University, } \\
\text { Eldoret; }\end{array}$ & 2 & $9.5 \%$ & 11 & 2 \\
\hline & & Kihara, T. & $\begin{array}{l}\text { Moi University, } \\
\text { Eldoret; }\end{array}$ & 2 & $9.5 \%$ & 11 & 2 \\
\hline & & Makori, E. & $\begin{array}{l}\text { University of } \\
\text { Nairobi }\end{array}$ & 2 & $9.5 \%$ & 2 & 1 \\
\hline
\end{tabular}

${ }^{+}$The h-index is based on the Corpus of data used representing publications in Cloud Computing and not the researcher's overall h-index.

\subsubsection{Productive Institutions}

Further analysis was performed on the bibliometric data to unveil the most productive institutions in each country. The most productive institutions in each country are shown in Table 2. In comparison, Mohammed V University in Rabat, Rabat, Morocco, has the highest number of publications with 138 publications, amounting to $39 \%$ of the overall national research output in the subject of cloud computing. Two institutions emerged tops in Kenya, University of Nairobi, Nairobi and Moi University, Eldoret, with each having three publications amount to a total of $34 \%$ of national scholarly contribution to cloud computing research. 
Table 2

Most Productive Institutions on Cloud Computing Research in Africa

\begin{tabular}{|c|c|c|c|c|}
\hline$\#$ & Institution's Name & Country & $\begin{array}{c}\text { Publication } \\
\text { Count }\end{array}$ & $\begin{array}{c}\% \text { of National } \\
\text { Output }\end{array}$ \\
\hline 1 & Mohammed V University in Rabat, Rabat* & Morocco & 138 & $39 \%$ \\
\hline 2 & University of Sfax, Sfax & Tunisia & 89 & $28 \%$ \\
\hline 3 & Ain Shams University, Cairo & Egypt & 71 & $24 \%$ \\
\hline 4 & University of Pretoria, Pretoria & South Africa & 41 & $18 \%$ \\
\hline 5 & Constantine II University, Constantine & Algeria & 34 & $19 \%$ \\
\hline 6 & Covenant University, Ogun State & Nigeria & 22 & $29 \%$ \\
\hline 7 & University of Khartoum, Khartoum & Sudan & 8 & $26 \%$ \\
\hline 8 & $\begin{array}{l}\text { Ghana Institute of Management and Public } \\
\text { Administration, Accra* }\end{array}$ & Ghana & 6 & $38 \%$ \\
\hline \multirow{2}{*}{9} & University of Nairobi, Nairobi; & \multirow{2}{*}{ Kenya } & 3 & $14 \%$ \\
\hline & Moi University, Eldoret & & 3 & $14 \%$ \\
\hline
\end{tabular}

${ }^{*}$ Merged publications data of variants of the institution names; e.g. publication count of ENIAS-Mohammed V University was merged with Mohammed V University

\subsection{Cloud Computing Popularity and Research Outputs}

In other to understand the online search behaviour of the cloud computing researchactive African countries, a Google trends exploration was performed for the term "cloud computing". The goal of the exploration was to identify the search volume which is an indicator of interest in the topic from those regions.

\subsubsection{Search Interest by Year}

In the light of the global search trends on cloud computing Figure 8 shows that South Africa emerged as the country with the highest aggregate search volume on the term, with an aggregated search volume of 4,449 followed by Morocco $(3,964)$, Tunisia $(3,303)$, Nigeria $(3,200)$, Egypt (3172), Algeria (2490), Ghana (2447), Kenya (2128) and Sudan (1498). We also observed that the year with the highest number of searches in Morocco was in 2012 (825). Similarly, the highest searches for other countries include: Tunisia (Year, 2012; Search volume, 623), Egypt (Year, 2012; Search Volume, 594), South Africa (Year, 2011; Search Volume, 862), Algeria (Year, 2012, Search Volume, 399), Nigeria (Year, 2011; Search Volume, 887), Sudan (Year, 2014: Search Volume, 333), Kenya (Year, 2011; Search Volume, 540), and Ghana (Year, 2011; Search Volume, 448). We observed that the peak year for the term "cloud computing" globally was also in 2011, with search volume over 1000.

\subsubsection{Search Interest by Sub-region}

Google trends provide the means to unveil interest by sub-region, and this indicates the locations from where the search term "cloud computing" was most popular during the 




Figure 8

Online Search Traffic on “Cloud Computing" from 2010-2017

time frame specified (2010-2017). The search term popularity values are scaled from 0 to 100 as a ratio of total searches in that location; where 100 is the location where the search term is most popular. In Table 3, we show the top 9 African countries where cloud computing research is most active, viz a viz the sub-regions where the search term cloud computing was most popular, as well as the most research-productive institutions in that region.

Table 3

Cloud Computing Interest by Sub-Region

\begin{tabular}{|c|c|c|c|c|}
\hline$\#$ & Country & Sub-Region & $\begin{array}{c}\text { Search } \\
\text { Popularity }\end{array}$ & $\begin{array}{c}\text { Most Research Productive Institution } \\
\text { in Region }\end{array}$ \\
\hline 1 & Morocco & $\begin{array}{l}\text { Rabat - Sale - Zemmour- } \\
\text { Zaer }\end{array}$ & 100 & $\begin{array}{l}\text { Mohammed V University in Rabat } \\
\text { Rabat }\end{array}$ \\
\hline \multirow{2}{*}{2} & \multirow{2}{*}{ Egypt } & Cairo Governorate & 100 & \multirow{2}{*}{ Ain Shams University, Cairo } \\
\hline & & Giza Governorate & 81 & \\
\hline 3 & Tunisia & Tunis & 100 & University of Sfax, Sfax \\
\hline \multirow{3}{*}{4} & \multirow{3}{*}{$\begin{array}{l}\text { South } \\
\text { Africa }\end{array}$} & Eastern Cape & 94 & \multirow{3}{*}{$\begin{array}{l}\text { The University of Pretoria, } \\
\text { Pretoria ( Province of Gauteng ) }\end{array}$} \\
\hline & & Limpopo & 100 & \\
\hline & & Gauteng & 79 & \\
\hline 5 & Algeria & Algiers Province & 100 & Constantine II University, Constantine \\
\hline 6 & Nigeria & Ogun State & 100 & Covenant University, Ogun \\
\hline 7 & Sudan & Khartoum & 100 & University of Khartoum, Khartoum \\
\hline 8 & Kenya & Nairobi & 100 & University of Nairobi, Nairobi \\
\hline 9 & Ghana & Greater Accra Region & 100 & $\begin{array}{l}\text { Ghana Institute of Management } \\
\text { and Public Administration, Accra }\end{array}$ \\
\hline
\end{tabular}




\subsection{Search Volume and Research Output}

We observed a statistically significant correlation $(\rho=0.767, p<0.05)$ between the aggregated search volume and the aggregated research outputs from the nine countries. Figure 9 shows the relationship between the aggregated search volume ratio and the overall research outputs from all the countries in the period under review. However, the analysis on a country basis showed significant statistical negative correlations for only four countries namely Egypt, Nigeria, South Africa and Ghana. With the exception of Sudan, other countries had negative correlation coefficients, although the correlation is not statistically significant (see Table 4).

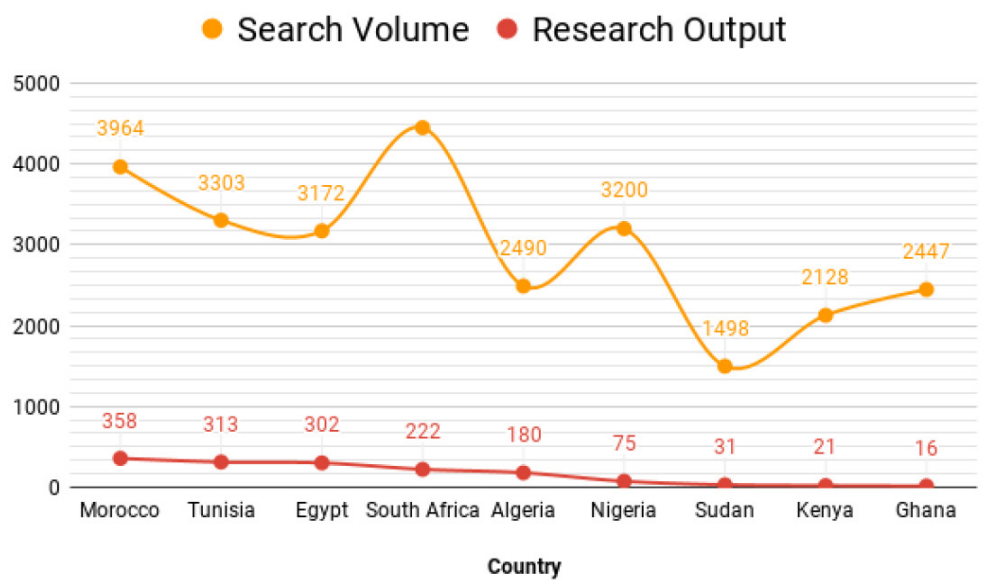

Figure 9

Relationship between Aggregated search Volume and Research Output

Table 4

Correlation of Search Volume with Research Output (Country Analysis)

\begin{tabular}{|l|l|c|c|c|}
\hline \multicolumn{1}{|c|}{ Country } & Corr & p-Value & Sign. \\
\hline 1 & Sudan & 0.122 & 0.774 & $\mathrm{~N}$ \\
\hline 2 & Tunisia & -0.383 & 0.349 & $\mathrm{~N}$ \\
\hline 3 & Kenya & -0.516 & 0.191 & $\mathrm{~N}$ \\
\hline 4 & Morocco & -0.599 & 0.117 & $\mathrm{~N}$ \\
\hline 5 & Algeria & -0.690 & 0.058 & $\mathrm{~N}$ \\
\hline 6 & Egypt & -0.886 & 0.003 & $\mathrm{Y}$ \\
\hline 7 & Nigeria & -0.898 & 0.002 & $\mathrm{Y}$ \\
\hline 8 & South Africa & -0.952 & 0 & $\mathrm{Y}$ \\
\hline 9 & Ghana & -0.970 & 0 & $\mathrm{Y}$ \\
\hline
\end{tabular}




\subsection{Internet Penetration and Scholarly Outputs}

There was a strong significant correlation between internet penetration and the total number of scholarly outputs within the given period for all countries studied $(\rho=0.775$, $\mathrm{p}<.01$ ). This suggests that an increase in internet penetration is directly proportional to increase in cloud computing research activities and outputs from a given region. We also performed correlation for each country's research outputs in cloud computing viz a viz the rate of internet penetration. The details of the correlation results for each country are shown in Table 5. All countries, except Kenya, show significant positive correlations of internet penetration and research outputs from the region.

Table 5

Spearman Rho Correlation Coefficient (Internet Penetration Vs Research Outputs)

\begin{tabular}{|l|l|c|c|c|}
\hline \multicolumn{1}{|c|}{ Country } & $\rho$ Corr & p-Value & Significant \\
\hline 1 & Egypt & 0.994 & 0.00 & Yes \\
\hline 2 & Tunisia & 0.994 & 0.00 & Yes \\
\hline 3 & Algeria & 0.976 & 0.00 & Yes \\
\hline 4 & South Africa & 0.976 & 0.00 & Yes \\
\hline 5 & Nigeria & 0.970 & 0.00 & Yes \\
\hline 6 & Morocco & 0.946 & 0.00 & Yes \\
\hline 7 & Ghana & 0.945 & 0.00 & Yes \\
\hline 8 & Sudan & 0.878 & 0.00 & No \\
\hline 9 & Kenya & 0.611 & 0.12 & \\
\hline
\end{tabular}

\section{Discussion}

Our results confirm that the amount of internet penetration and the volume of online search traffic on the term "cloud computing" individually and positively correlate with the volume of publications on cloud computing research from developing countries in Africa.

Generally, the positive increase in the percentage of access to the internet over the period under review is a positive indicator of growth that must have impacted both research and development in the countries studied. As of 2017, the countries with above $45 \%$ internet penetration among the countries studied include Morocco, Tunisia, South Africa, Algeria, and Egypt. Eighty per cent of this list of countries with over $45 \%$ internet penetration comprises of countries in the Northern region of Africa. This is both instructive and indicative of the level of Governmental investments in promoting the development of ICT (AfDB, 2018). These investments have paid off since increase in the rate of internet penetration led to corresponding increase in research output, and in most cases almost a correlation coefficient of 1 (see Table 5). Generally, countries in the northern region with higher internet penetration rates had higher publication counts. 
The aggregated number of publications on cloud computing research from Africa is very small, amounting to less $0.5 \%$ of the total global publication volume on the subject matter. However, it was discovered that the most productive institutions in cloud computing from each country are also highly placed in either the webometric ${ }^{3}$ or the ranking of world universities by Times Higher Education ${ }^{4}$; these rankings are an indication of the quality of academic endeavours in those institutions.

Again, we realized from the regional analysis that countries from the Northern part of Africa (i.e. Morocco, Tunisia, Egypt, Algeria and Sudan) account for more than $50 \%$ of the top contributing countries and are responsible for over $78 \%$ of the total publications from the continent. With the exception of Sudan, this trend is also consistent with the analysis of the rate of internet penetration. A number of bibliometrics studies and reports (Blom et al., 2015; Fonn et al., 2018), have shown that the Northern region of Africa have higher research outputs; likewise, the results of this study provide evidence of more active research activities in cloud computing from the Northern region of Africa, in comparison to the other regions of the continent. This effectiveness can also be further explained by the GDP data, researcher per million, and growth of research in the region, as a consequence of the quality of universities and research institutions as promoted by favourable government policies and investments.

On the online search traffic analysis on the term "cloud computing", our results show that the term "cloud computing" degraded after a number of years. The search volume ratio peaked in the years 2010, 2011 and 2012, for most of the countries, and the year 2011 being the mode peak year. However, in Sudan, the search volume ratio peaked in 2014 . For most of the countries, the peak year for the search volume ratio is also close to the average global peak year for the term according to Google trends, i.e. 2011.

Interestingly, the sub-regional analysis of the popularity of the search term shows that the highest volume of searches on cloud computing came from regions where the most productive institutions were also located. It can be deduced from Table 3 that a high number of the most productive institutions in each country are located in the sub-regions with high interests in "cloud computing". The level of interest in the subject of cloud computing, as evident by the data, is speculated as to the basis for the high number of publications from those institutions.

Although the aggregated search volume related positively with the number of research publications, there were negative correlations obtained when analysis was performed on a country basis (see Table 4). A possible explanation could be that the knowledge of and expertise in cloud computing were established in the earlier years (i.e. 2010 and 2011), and afterwards, researchers in the region began to make contributions to the subject domain. In other words, the initial curiosity and high interest in cloud computing contributed to the buildup of momentum for eventual contributions in the domain, which became evident in the volume of publications in subsequent years.

3 www.webometrics.info

4 www.timeshighereducation.com 
We acknowledge two limitations to this study. First, the bibliometric information of research outputs from the countries was sourced from a single database, i.e. the Scopus Database. It will be interesting to know what pattern of results will emerge from the use of or combination of results from other databases like Clarivate Analytics' Web of Science (WoS), EBSCO Host, Google Scholar, etc. Second, the online search traffic data used in this study is limited to those obtained from the Google search engine as accessed through Google trends. Online search data from other search engines like Bing, and/or Yahoo could possibly have an effect on the results obtained. Furthermore, the curiosity and interest in the concept of cloud computing may have been fulfilled through access to other non-web resources like printed or electronic resources, which was not captured in this study. These possibilities will be explored as part of future research.

\section{Conclusion}

The internet, like in other areas, promotes research inclusion by reducing the cost of access to information. The results of this study show that an increase in internet access can improve the quantity, and possibly, the quality, of research in Africa. Similarly, the analysis of online search traffic data has the potential to predict research productivity from a given region. This study adds weight of evidence and a call for stakeholders to take actions towards a sustainable future for Africa. With greater investments in technology and research education, as well as ICT infrastructures by the government of these regions, it is expected that African researchers can increase their contributions to the global knowledge outputs subsequently.

\section{Acknowledgements}

The funding for this research is provided by the Covenant University Center for Research Innovation and Discovery (CUCRID).

\section{References}

[1] AfDB. (2018). African Economic Outlook. In Africa Develoment Bank (AfDB). https:/ /www. afdb.org/fileadmin/uploads/afdb/Documents/Publications / African_Economic_Outlook_2018_-_EN.pdf

[2] Al-Shammari, S., \& Al-Yasiri, A. (2014). Defining a Metric for Measuring QoE of SaaS Cloud Computing. Proceedings of PGNET, 251-256. http://www.cms.livjm.ac.uk/PGNet2014/papers/1569959019.pdf

[3] Blom, A., Lan, G., \& Adil, M. (2015). Sub-Saharan African Science, Technology, Engineering, and Mathematics Research: A Decade of Development. In Sub-Saharan African Science, 
Technology, Engineering, and Mathematics Research: A Decade of Development. https://doi. org/10.1596/978-1-4648-0700-8

[4] Bornmann, L., \& Daniel, H. D. (2009). The state of $h$ index research. Is the $h$ index the ideal way to measure research performance? EMBO Reports, 10(1), 2-6. https://doi. org/10.1038/embor.2008.233

[5] Cai, Y., Lu, W., Wang, L., \& Xing, W. (2015). Cloud Computing Research Analysis Using Bibliometric Method. International Journal of Software Engineering and Knowledge Engineering, 25(03), 551-571. https:/ / doi.org/10.1142/S0218194015400203

[6] Carrière-Swallow, Y., \& Labbé, F. (2013). Nowcasting with Google trends in an emerging market. Journal of Forecasting. https:/ / doi.org/10.1002/ for.1252

[7] Carta, S., Medda, A., Pili, A., Recupero, D. R., \& Saia, R. (2018). Forecasting E-commerce products prices by combining an autoregressive integrated moving average (ARIMA) model and Google Trends data. Future Internet. https:/ / doi.org/10.3390/fi11010005

[8] Dergiades, T., Mavragani, E., \& Pan, B. (2018). Google Trends and tourists' arrivals: Emerging biases and proposed corrections. Tourism Management. https://doi.org/10.1016/j. tourman.2017.10.014

[9] Duermeijer, C., Amir, M., \& Schoombee, L. (2018). Africa generates less than 1\% of the world's research; data analytics can change that. Elsevier Connect.

[10] Dumon, O. (2013). How the Internet Changed Science Research and Academic Publishing, Creating the New Research Economy | HuffPost. https://www.huffingtonpost.com/olivier-dumon/how-the-internet-changed_b_2405006.html

[11] Elsevier. (2016). Scopus. SCOPUS. https://www.elsevier.com/solutions/scopus

[12] Ezenwoke, A., \& Igbekele, E. (2019). Cloud Computing Research in Nigeria: A Bibliometric and Content Analysis. Asian Journal of Scientific Research, 12(1), 41-53. https:/ / doi. org/10.3923/ajsr.2019.41.53

[13] Fonn, S., Ayiro, L. P., Cotton, P., Habib, A., Mbithi, P. M. F., Mtenje, A., Nawangwe, B., Ogunbodede, E. O., Olayinka, I., Golooba-Mutebi, F., \& Ezeh, A. (2018). Repositioning Africa in global knowledge production. In The Lancet. https://doi.org/10.1016/S01406736(18)31068-7

[14] Foroughi, F., Lam, A. K.-Y., Lim, M. S. ., Saremi, N., \& Ahmadvand, A. (2016). “Googling” for Cancer: An Infodemiological Assessment of Online Search Interests in Australia, Canada, New Zealand, the United Kingdom, and the United States. JMIR Cancer. https:/ / doi. org/10.2196/cancer.5212

[15] Gartner. (2016). Public Cloud Services, Worldwide, 2011-2016, 4Q12 Update. www.gartner. $\mathrm{com} / \mathrm{resId}=2332215$ 
[16] Hirsch, J. (2005). An index to quantify an individual's scientific research output. Proceedings of the National Academy of Sciences of the United States of America. https: / /arxiv.org/ pdf/physics /0508025\%29

[17] IBM-Corp. (2019). IBM SPSS Statistics for Windows (Version 25.0).

[18] International Telecommunication Union. (2018). Measuring the Information Society Report Volume 1 2018. In International Telecommunication Union.

[19] Kemp, S. (2018). Digital in 2018: World's internet users pass the 4 billion mark. In We Are Social. https:/ / doi.org/10.1016/j.jinorgbio.2012.07.019

[20] Kholodilin, K. A., Podstawski, M., \& Siliverstovs, B. (2010). Do Google Searches Help in Nowcasting Private Consumption? A Real-Time Evidence for the US. In SSRN. https:// doi.org/10.2139/ssrn.1615453

[21] Mavragani, A., \& Ochoa, G. (2018). Forecasting AIDS prevalence in the United States using online search traffic data. Journal of Big Data, 5(1). https://doi.org/10.1186/s40537-0180126-7

[22] Nuti, S. V., Wayda, B., Ranasinghe, I., Wang, S., Dreyer, R. P., Chen, S. I., \& Murugiah, K. (2014). The use of google trends in health care research: A systematic review. In PLoS ONE. https://doi.org/10.1371/journal.pone.0109583

[23] Preis, T., Moat, H. S., \& Stanley, H. E. (2013). Quantifying trading behavior in financial markets using google trends. Scientific Reports, 3. https:/ / doi.org/10.1038/srep01684

[24] Ramgovind, S., Eloff, M. M., \& Smith, E. (2010). The management of security in cloud computing. Proceedings of the 2010 Information Security for South Africa Conference, ISSA 2010. https: / / doi.org/10.1109/ISSA.2010.5588290

[25] Rech, J. (2007). Discovering trends in software engineering with google trend. ACM SIGSOFT Software Engineering Notes. https:/ / doi.org/10.1145/1234741.1234765

[26] Rivera, R. (2016). A dynamic linear model to forecast hotel registrations in Puerto Rico using Google Trends data. Tourism Management, 57, 12-20. https:/ /doi.org/10.1016/j.tourman.2016.04.008

[27] Sampath Kumar, B. T., \& Manjunath, G. (2013). Internet use and its impact on the academic performance of university teachers and researches A comparative study. Higher Education, Skills and Work-Based Learning, 3(3), 219-238. https://doi.org/10.1108/HESWBL-09-2011-0042

[28] Tuitoek, D., Chelangat, S., Sulo, T., Kendagor, R., \& Kosgei, D. (2012). Factors affecting research productivity in public university of Kenya: The Case of Moi University Eldoret. Journal of Emerging Trends in Economics and Management Sciences, 3(5), 475-484. 
[29] Vinkler, P. (2019). Core journals and elite subsets in scientometrics. Scientometrics, 121(1), 241-259. https://doi.org/10.1007/s11192-019-03199-5

[30] Weng, B., Lu, L., Wang, X., Megahed, F. M., \& Martinez, W. (2018). Predicting short-term stock prices using ensemble methods and online data sources. Expert Systems with Applications, 112, 258-273. https:/ / doi.org/10.1016/j.eswa.2018.06.016

[31] Woo, J., \& Owen, A. L. (2019). Forecasting private consumption with Google Trends data. Journal of Forecasting, 38(2), 81-91. https:/ / doi.org/10.1002/for.2559

[32] Yelowitz, A., \& Wilson, M. (2015). Characteristics of Bitcoin users: an analysis of Google search data. Applied Economics Letters. https://doi.org/10.1080/13504851.2014.995359

[33] Zyoud, S. H., \& Fuchs-Hanusch, D. (2017). Estimates of Arab world research productivity associated with groundwater: a bibliometric analysis. Applied Water Science, 7(3), 12551272. https:/ / doi.org/10.1007/s13201-016-0520-2

[34] Zyoud, S. H., \& Fuchs-Hanusch, D. (2020). Mapping of climate change research in the Arab world: a bibliometric analysis. Environmental Science and Pollution Research, 27(3), 3523-3540. https:/ /doi.org/10.1007/s11356-019-07100-y 